\title{
Interference of Some Organic Substances and Microorganisms Adhered to Stainless Steel in ATP- bioluminescence Measurement
}

\author{
Erny Marcelo Simm ${ }^{1}$, Nélio José de Andrade ${ }^{2^{*}}$, Regina Célia Santos Mendonça ${ }^{2}$, Frederico \\ José Vieira Passos ${ }^{2}$ and José Benício Paes Chaves ${ }^{2}$ \\ Universidade Federal de Viçosa; Viçosa - MG - Brazil. ${ }^{2}$ Departamento de Tecnologia de Alimentos, Universidade \\ Federal de Viçosa; 36570-000; Viçosa - MG - Brazil
}

\begin{abstract}
Adhesion of organic substances and microorganisms on stainless steel surface was evaluated. The log RLU measurement was affected at a lower or higher degree, by type or concentration of the organic substances (casein, lipid, sucrose and their combinations) adhered to surface. However, if the samples analyzed were from the food processing surfaces, they would have been considered to be under satisfactory hygienic conditions with log RLU $\leq$ 2.18 ( $\leq 150 R L U)$. The log RLU measurements of Staphylococcus carnosus-adhered surfaces, combined with or without the organic substances, were higher $(p<0.05)$ than those of the Bacillus subtilis spores-adhered surface, regardless of the concentration. The samples taken from the surfaces adhered with the casein, lipid, sucrose and $2.9 \times 10^{1} \mathrm{DMC} . \mathrm{cm}^{-2}$ and $2.9 \times 10^{2} \mathrm{DMC}^{-\mathrm{ml}^{-1}}$ did not have any significant differences $(p \geq 0.05)$ on ATP-bioluminescence measurements. However, the surfaces adhered with $2.9 \times 10^{3}$ DMC.cm ${ }^{-2}$ of B. subtilis spores and organic substances showed an increase in the log RLU measurement compared to surfaces containing only the organic substances.
\end{abstract}

Key words: Hygiene monitoring; ATP-bioluminescence measurement; Adhesion on stainless steel

\section{INTRODUCTION}

Rapid methods have been developed to evaluate the hygienic conditions of contact surfaces in the food processing. ATP-bioluminescence is one of the techniques most widely applied in the food industry for such purpose. This technique detects the amount of ATP on contact surfaces in the food processing systems (Costa et al., 2006; Parizzi et al. 2004; Costerton et al., 1987; Griffith et al., 2000). The use of this technique to determine whether a surface is hygienically fit for the food processing will increase with the increase of the implementation the HACCP (Hazard Analysis and Critical Control Points) system in the Brazilian food industry. Despite the extensive research conducted on ATP-bioluminescence, several factors that may affect Relative Light Unit measurement should be further investigated such as the influence of the bacterial spores.

The food industries need further their understanding of the bioluminescence measurement.

The objective of this study was to evaluate the effect of the casein, lipid, sucrose, Staphylococcus carnosus and Bacillus subtilis spores, combined or not, adhered to stainless steel surfaces on ATPbioluminescence measurement.

*Author for correspondence 


\section{MATERIALS AND METHODS}

\section{Organic substance suspensions}

The interference of the suspensions containing 3.5, 7.0 and $11.0 \mathrm{mg} \cdot \mathrm{ml}^{-1}$ of casein (Sigma) and 7.0, 14.0 and $21.0 \mathrm{mg} \cdot \mathrm{ml}^{-1}$ of animal fat (lard, Sadia ) and 0.6, 1.2 and $1.8 \mathrm{mg}^{-\mathrm{ml}^{-1}}$ of sucrose (Vetec) was evaluated. These previously determined amounts corresponded approximately to the amounts of protein, fat and sucrose residues found on the stainless steel surfaces after the hygienic procedures following the simulation of processing of a meat product (Italian salami). A sample was prepared by using $500 \mathrm{~g}$ of pork and $500 \mathrm{~g}$ of lard ground in a meat grinder (Roabster) using a $5 \mathrm{~mm}$ diameter disc. Three stainless steel coupons (AISI 304, \#4, 100mmx100mmx10mm), sterilized at $121^{\circ} \mathrm{C} / 15 \mathrm{~min}$ were placed in contact with the meat sample for 10 minutes. The coupons were submitted to a pre-rinse with the water $\left(20-25{ }^{\circ} \mathrm{C}\right)$ and cleaned with the based-surfactant detergent (manually applied with polyurethane brush). The protein, lipid and carbohydrate residue concentrations remaining on the surface were determined (AOAC, 1998)

\section{Staphylococcus carnosus suspensions}

A pure culture of $S$. carnosus kept on semi-solid Brain-Heart Infusion (BHI-Biobras) and glycerol $(80: 20)$ at $-80{ }^{\circ} \mathrm{C}$ was activated by three inoculation transfers in BHI broth allowed to grow for $24 \mathrm{~h} / 35{ }^{\circ} \mathrm{C}$. The bacterial number reached approximately $10^{9}$ DMC.ml ${ }^{-1}$ (Direct Microscopic Count per $\mathrm{ml}$ ), by microscopy according to methodology described by Evancho et al. (2001). From the concentrated suspension, spores in sterilized $0.31 \mathrm{M}$ phosphate buffer $(\mathrm{pH} 7.0 \pm 0.1)$ were adhered to the surfaces $\left(5.4 \times 10^{3}\right.$ DMC. $\mathrm{cm}^{-2}$ to $5.4 \times 10^{1}$ DMC.cm ${ }^{-2}$ )

\section{Bacillus subtilis spore suspensions}

From a pure culture of $B$. subtilis isolated from the raw milk and kept on PCA (Merck) at $-80{ }^{\circ} \mathrm{C}$, spores suspensions were prepared according to Akutsu (2001) and kept in $1 \mathrm{ml}$ Eppendorf tubes stored at $-80{ }^{\circ} \mathrm{C}$. The spores concentration $\left(\mathrm{DMC} \cdot \mathrm{ml}^{-1}\right)$ in the final suspension was determined by the phase contrast microscopy, according to Evancho et al. (2001). From the concentrated suspension, the spores in the sterilized $0.31 \mathrm{M}$ phosphate buffer $(\mathrm{pH} 7.0 \pm 0.1)$ were adhered to the surfaces $\left(2.9 \times 10^{3}\right.$ DMC. $\mathrm{cm}^{-2}$ to $2.9 \times 10^{1}$ DMC. $\mathrm{cm}^{-2}$ )

The adherence of the suspensions to the stainless steel surface, the interference of the suspensions of the organic substances and microorganisms, combined or not, adhered to the stainless steel surface in the measurement was evaluated (Table $1)$.

The microorganisms were inoculated on the surface at concentrations ranging from $5.4 \times 10^{1}$ DMC.cm ${ }^{-2}$ to $5.4 \times 10^{3}$ DMC.cm ${ }^{-2}$ for $S$. carnosus and from $2.9 \times 10^{1} \mathrm{DMC}^{-\mathrm{cm}^{-2}}$ to $2.9 \times 10^{3} \mathrm{DMC}$. $\mathrm{cm}^{-2}$ for B. subtilis spores.

Table 1 - Organic substances or microorganisms, combined or not, adhered to stainless steel surface

$\begin{array}{ll}\text { Organic substances } & \text { i) casein; ii) lipid iii) sucrose iv) casein + sucrose v) casein }+ \text { lipid }, \\ & \text { vi) lipid + sucrose; vii) casein }+ \text { sucrose }+ \text { lipid } \\ \text { Microorganisms } & \text { i) Staphylococcus carnosus; } \\ & \text { ii) ii) Bacillus subtilis spores }\end{array}$

$\begin{array}{ll}\text { Organic substances } & \text { i) casein + sucrose + lipid + Staphylococcus carnosus; } \\ \text { Microorganisms } & \text { ii) casein + sucrose + lipid + Bacillus subtilis spores }\end{array}$

The concentration chosen was the one that allowed RLU measurement and was also compatible with the degree of contamination in the utensils and the surfaces in contact with the food. One $\mathrm{ml}$ of each suspension or solution was aseptically and uniformly distributed in the drops on the surface of the stainless steel coupons $(100 \mathrm{~mm} \times 100 \mathrm{~mm} \times 10$ $\mathrm{mm}$ ), using a sterilized automatic pipette. Eight drops were applied vertically and nine, horizontally, totaling 72 drops. The coupons were maintained in a hood (laminar flow) for 30 minutes at $35{ }^{\circ} \mathrm{C}$, followed by the determination of 
the RLU measurement by the ATPbioluminescence.

\section{RLU measurements}

The samples from the stainless steel surfaces adhered with the organic substances and/or microorganisms were submitted to the RLU measurement by using the Clean Trace kit (Biotrace). The ATP was sampled by rubbing the swabs twice on the surface of the previously adhered coupons, diagonally at a $30^{\circ}$ angle, over the entire area. The swabs were introduced into a cuvette containing the luciferin-luciferase enzymatic complex to which the ATP sampled surfaces reacted forming light. The kits were introduced into the luminometer and the bioluminescence measurements were determined after approximately 10 seconds. The results were expressed as $\log _{10}$ RLU. According to Biotrace (2000) recommendations, equipments and utensils surfaces may be considered satisfactory hygienic conditions when present bioluminescence measurements $\leq 150 \mathrm{RLU}$; under alert conditions, between 151 to 300 RLU and under unsatisfactory hygienic conditions when > 301 RLU.

\section{Statistical analyses}

The data were evaluated by the Statistical Analysis System (SAS-2004) procedures, as follows: i) Combinations of the organic substances adhered to the stainless steel coupons were evaluated by an experiment arranged in a completely randomized design, with seven treatments and three repetitions. The RLU measurements were in duplicate. The comparisons were performed by the $\mathrm{F}$ test; ii) Combinations of the organic substances adhered to the stainless steel coupons combined with $S$. carnosus or $B$. subtilis spores were evaluated in an experiment arranged in a completely randomized design in five treatments and three repetitions. The RLU measurements were in duplicate. The comparisons were tested by the F test; iii) The differences in the RLU number for $S$. carnosus and $B$. subtilis spores were evaluated by the student $t$ test. The experiment was conducted in three repetitions in duplicate; iv) The differences in the RLU number for the suspensions with the organic substances combined with $S$. carnosus and $B$. subtilis spores were evaluated by the student $t$ test. The experiment was conducted in three repetitions in duplicate; v) Data for the three organic substances combined with $S$. carnosus or B. subtilis spores were evaluated by the descriptive analysis.

\section{RESULTS AND DISCUSSION}

\section{Interference of organic substances}

The surfaces adhered with one, two or three organic substances showed different log RLU measurements when combined (Table 2). The samples with the casein plus lipid showed a significant reduction in the $\log$ RLU $(\mathrm{p}<0.05)$ compared to the samples of the casein only. No significant difference $(p \geq 0.05)$ was found in the $\log$ RLU measurement between the samples from the surfaces adhered with the casein plus sucrose and the samples of the casein as the substance organic adhered. Similar result was found for the casein plus lipid compared to the lipid, or lipid plus sucrose samples containing only one of these substances. Also, there was no significant difference in the log RLU ( $p<0.05)$ in the sample from the surfaces adhered with the three substances, compared to the casein plus sucrose. Finally, a significant increase $(\mathrm{p}<0.05)$ in the $\log$ RLU was observed in the samples of casein plus lipid plus sucrose suspension, compared to the casein plus lipid and lipid plus sucrose.

Table 2 - Average and standard deviation of the $\log _{10}$ of the RLU number of organic substances adhered to stainless steel.

\begin{tabular}{lc}
\hline & Average $(\underline{\underline{+\sigma}})$ \\
\hline Casein & $2.06(0.12)$ \\
Lipid & $1.82(0.12)$ \\
Sucrose & $1.77(0.05)$ \\
Casein + lipid & $1.90(0.17)$ \\
Casein + sucrose & $2.08(0.05)$ \\
Lipid + sucrose & $1.95(0.11)$ \\
Casein + lipid + sucrose & $2.07(0.09)$ \\
\hline
\end{tabular}


According to Biotrace (2000), if the samples analyzed were from the food processing surfaces, they would have been considered to be under satisfactory hygienic conditions with $\log \mathrm{RLU} \leq 2.18$ ( $\leq 150 \mathrm{RLU})$.

Interference of type and number of microorganisms in RLU measurement

The $\log$ RLU number increased with increased microorganism concentration for $S$. carnosus and
B. subtilis spore suspensions, combined with or without the organic substances, adhered to stainless steel. The log RLU number was higher for the vegetative cell suspensions than for those containing the bacterial spores (Fig. 1)

Such difference can be explained based on the low ATP content levels in the spores. The spores were in a dormant stage with no detectable metabolism at low concentrations of the intracellular ATP and the absence of electron transport.

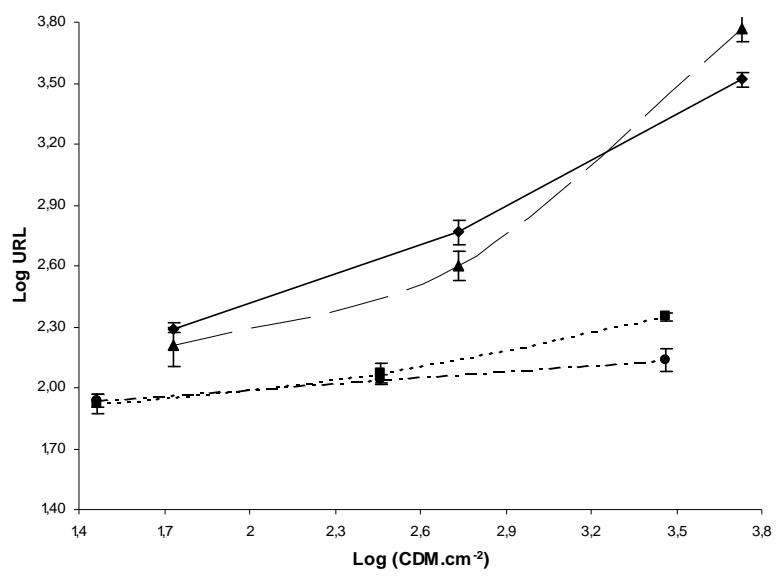

Figure $1-\log _{10}$ of the RLU number of microorganisms adhered to stainless steel AISI 304, \#4. $\mathbf{\Delta}$----Staphylococcus carnosus; $\quad \mathbf{\Delta}$ - casein + lipid + sucrose + Staphylococcus carnosus; - Bacillus subtilis spores; • casein + lipid + sucrose + Staphylococcus carnosus

These factors lead to a reduced log RLU measurement. Kodaka et al. (1996) found a concentration of $10^{-21} \mathrm{~mol}$ of the ATP per bacterial spores and $10^{-17}$ mol per vegetative cell. It mean that the ATP concentration in the bacterial spores was ten thousand times lower. This fact also explain the difference $(p<0.1)$ in the average log RLU number between the suspensions containing the casein plus lipid plus sucrose when combined with $2.9 \times 10^{3}$ DMC.cm ${ }^{-2}$ of $B$. subtilis spores ( 2.14) or $5.4 \times 10^{3}$ of $S$. carnosus (3.53). Thus, the $\log$ RLU values above 2.48 (300 URL) for $S$. carnosus suspension would indicate unsatisfactory hygienic conditions if the samples were from the processing surfaces while the surfaces for $B$. subtilis spore suspensions reaching values below 2.14 ( $<150$ URL) would be in satisfactory hygiene conditions.

Low $\log$ RLU numbers were expected for the organic substances since in these compounds there was no ATP. However, some studies suggested a probable influence of the surface organic matter residues on the enzymatic reaction that produced the light signal measured by the luminometer (Krisinsky et al, 1992). According to the Velasquez et al. (1997) the quenching and enhancement occurred by the ATP extractants, cleaners and sanitizers affecting the detection of the ATP bioluminescence measurements.

\section{Interference of organic substances combined with microorganisms}

The $\log$ RLU number increased $(\mathrm{p}<0.05)$ significantly for all the suspensions containing the casein, lipid and sucrose combined with $S$. carnosus adhered to stainless steel surface, compared with those containing only the organic substances (Table 3 ). 
Table 3 - Average and standard deviation of the $\log _{10}$ of RLU of organic substances, combined with microorganisms, adhered to stainless steel AISI 304, \#4.

\begin{tabular}{lc}
\hline Adhesion of organic substances and, or, microorganisms & Average $( \pm \sigma)$ \\
\hline $\mathrm{C}+\mathrm{L}+\mathrm{S}$ & $2.07(0.09)$ \\
S. carnosus $\left(5.4 \times 10^{3}\right)$ & $3.77(0.07)$ \\
S. carnosus $\left(5.4 \times 10^{2}\right)$ & $2.60(0.07)$ \\
S. carnosus $\left(5.4 \times 10^{1}\right)$ & $2.21(0.11)$ \\
B. spores $\left(2.9 \times 10^{3}\right)$ & $2.35(0.02)$ \\
B. subtilis spores $\left(2.9 \times 10^{2}\right)$ & $2.07(0.05)$ \\
B. subtilis spores $\left(2.9 \times 10^{1}\right)$ & $1.92(0.05)$ \\
$\mathrm{C}+\mathrm{L}+\mathrm{S}+$ S. carnosus $\left(5.4 \times 10^{3}\right)$ & $3.53(0.04)$ \\
$\mathrm{C}+\mathrm{L}+\mathrm{S}+$ S. carnosus $\left(5.4 \times 10^{2}\right)$ & $2.77(0.06)$ \\
$\mathrm{C}+\mathrm{L}+\mathrm{S}+$ S. carnosus $\left(5.4 \times 10^{1}\right)$ & $2.29(0.01)$ \\
$\mathrm{C}+\mathrm{L}+\mathrm{S}+$ B. subtilis spores $\left(2.9 \times 10^{3}\right)$ & $2.14(0.05)$ \\
$\mathrm{C}+\mathrm{L}+\mathrm{S}+$ B. subtilis spores $\left(2.9 \times 10^{2}\right)$ & $2.04(0.03)$ \\
$\mathrm{C}+\mathrm{L}+\mathrm{S}+$ B. subtilis spores $\left(2.9 \times 10^{1}\right)$ & $1.94(0.04)$ \\
\hline
\end{tabular}

C: casein; L: lipid; S: sucrose.

Numbers of microorganisms expressed in DMC.cm ${ }^{-2}$

These results showed the high difference in ATP concentrations between the two suspensions, confirming the small interference of the casein, lipid and sucrose in the bioluminescence measurement.

The $\log$ RLU number of the suspensions with $5.4 \times 10^{3}$ DMC. $\mathrm{cm}^{-2}$ of $S$. carnosus combined with the three organic substances was significantly lower $(p<0.05)$ than that of the microorganism suspension, both adhered to stainless steel (Table 3 ). From the results, it could be observed that the vegetative cell was the major ATP source in the suspension and that possible interaction between the bacterium and the organic substances affected the bioluminescence measurement. Richardson et al. (1980) investigated the distribution of these nucleotides in the bovine milk and confirmed the likelihood of the interaction between the ATP and casein to occur, preventing it to react with the luciferin and luciferase complex. This information allowed to infer that the lower the amount of organic substances in the suspension, the higher the $\log$ RLU number would be. Such inference was confirmed in this experiment for the casein and lipid suspensions that showed higher log RLU number in the suspensions with lower concentrations. However, this was not confirmed for sucrose and microorganism suspensions, which did not show any change in the log RLU number for different concentrations of this substance.

A significant increase $(p<0.05)$ in the log $R L U$ number was detected when comparing $5.4 \times 10^{2}$ DMC. $\mathrm{cm}^{-2}$ of $S$. carnosus combined with the three organic substances and the suspension containing only the microorganism, both adhered to stainless steel (Table 3). This result was different for the suspensions at concentration of $5.4 \times 10^{3}$ DMC.cm${ }^{2}$, as expected. If these samples were from the food processing surfaces, they would be considered to be under unsatisfactory hygienic conditions, with $\log$ URL values above 2.48 , according to the manufacturer's recommendations.

No significant difference $(\mathrm{p}<0.05)$ was detected in the $\log$ URL number when comparing between $5.4 \times 10^{1}$ DMC. $\mathrm{cm}^{-2}$ of $S$. carnosus combined with the three organic substances and the suspension containing only the microorganism, both adhered to the stainless steel (Table 3). In this case, it seemed that the number of microorganisms adhered to the surface could be below the number detectable by the bioluminescence technique and the presence of the organic substances was not sufficient to increase the ATP concentrations in the suspension containing only the microorganism. Food processing surfaces showing the same concentration of the microorganisms and the organic substances would be considered to be under alert hygienic conditions with the $\log$ RLU between 2.48 and 2.18, according to the manufacturer's recommendations.

The addition of $2.9 \times 10^{3}$ DMC. $\mathrm{cm}^{-2}$ spores organic substances increased $(\mathrm{p}<0.05)$ the $\log$ RLU number, compared with those containing casein, lipid or sucrose (Table 3). The comparison of the two other spore concentrations and the suspension with the three organic substances, adhered to the 
stainless steel, showed a decrease in log RLU. In all the cases, if the samples were from the food processing surfaces, they would have been considered under satisfactory hygienic conditions for the food processing, with the log RLU number below 2.18. This was a false negative result, which would allow spore-contaminated surfaces to be used in the food processing.

\section{CONCLUSIONS}

The log RLU measurement was affected at a lower or higher degree, by the type or concentration of the organic substances and microorganisms and their combinations. Due to their low ATP content, the bacterial spores were the factors that most interfered in the ATP-bioluminescence technique as the indicators of the hygienic conditions of the stainless steel surfaces. The surfaces with a high spore count would be approved for the food processing

The ATP determination on the surfaces should be used as an auxiliary tool to monitor the hygiene procedures, provided it was associated to other methods such as the microbial count. In addition, the food industry should be aware of the limitations of the ATP-bioluminescence equipments used.

\section{RESUMO}

A adesão de substâncias orgânicas e de microrganismos em cupons de aço inoxidável ASI 304, \#4 foi avaliada. A medida de Unidades Relativas de Luz (RLU) foi afetada em menor ou maior nível pelo tipo e concentração das substâncias orgânicas e suas combinações. Entretanto, se as amostras fossem oriundas de superfícies de processamento de alimentos, elas seriam consideradas em boas condições higiênicas pois as medidas de log URL ficaram abaixo de $2,18 \log (\leq 150 \mathrm{URL})$ com ou sem adição das substâncias orgânicas e independente da concentração estudada, as células vegetativas apresentaram número de log URL para $S$. carnosus maior $(\mathrm{p}<0,05)$ do que para os esporos de $B$. subtilis. Amostras de superfícies aderidas com caseína, lipídio e sacarose e $2.9 \times 10^{1} \mathrm{CDM}_{\mathrm{cm}} \mathrm{cm}^{-2}$ ou $2.9 \times 10^{2} \mathrm{CDM} \mathrm{ml}^{-1}$ não apresentaram diferença significativa $(\mathrm{p} \geq 0.05)$ na medida de ATP- bioluminescência. Entretanto, superfícies aderidas com 2.9 $\times 10^{3}$ CDM.cm ${ }^{-2}$ de esporos de B. subtilis e as substâncias orgânicas mostraram um aumento no $\log$ URL comparado com as superfícies contendo somente substâncias orgânicas.

\section{ACKNOWLEDGEMENTS}

The authors thank CNPq, CAPES and FAPEMIG, for the financial support to this research.

\section{REFERENCES}

Akutsu, C.K. (2001), Adesão de esporos de Bacillus sporothermodurans ao aço inoxidável e sua resistência a sanificantes químicos em condições de uso simulado. Dissertação de Mestrado, Universidade Federal de Viçosa, Viçosa, Minas Gerais, Brasil.

Association of Official Analytical Chemists (AOAC). (1998), Official methods of analysis. $16^{\mathrm{a}}$ ed., $4^{\mathrm{a}}$ revisão, Gaithersburg.

Biotrace. (2000), BIOTRACE Xcel. [S. I.]. Manual técnico, $140 \mathrm{p}$

Costa, P. D. C.; Andrade, N. J. ; Passos, F. J. V.; Brandão, S. C. C.; Freire, C. G. (2004) ATPbioluminescence as a technique to evaluate the microbiological quality of water in food industry. Braz. Arch. Biol. Technol. 49, 3, 399-405.

Costa, P. D. Andrade, N. J. ; Soares, N. F. F. ; Passos, J. F. V. Brandão S. C. C. (2006) . ATPbioluminescence assay as an alternative for hygienemonitoring procedures of stainless steel milk contact surfaces. Braz. .J Microbiol. 37, 345-349

Costerton, J. W.; Cheng, K. J.; Geesey, G. G.; Ladd, T. I.; Nickel, J. C.; Dasgupta, M.; Marrie, T. J. (1987), Bacterial bio films in nature and disease. Annual Review of Microbiol. 41, 435-464.

Evancho, G.M.; Sveum, W.H.; Moberg, L.J.; Frank, J. F. Microbiological Monitoring of the Foods Processing Environment.2001) In: DOWNES, F.P.; ITO, K. ed. Compendium of Methods for the Microbiological Examination of Foods. $4^{\text {th }}$. Chapter. 3 , p. $25-35$

Griffith, C. J.; Cooper, R. A.; Gilmore, J.; Davies, C.; Lewis, M. (2000), An evaluation of hospital cleaning regimes and standards. Journal of Hospital Infection, $45,19-28$.

Kodaka, H.; Fukuda, K.; Mizuochi, S.; Horigome, K. (1996) Adenosine triphosphate content of microorganisms related with food spoilage. Japanese Journal of Food Microbiology, 13, 29-34

Krysinski, E.P.; Brown, L.J.; Marchisello, T.J. (1992) Effect of cleaners and sanitizers on Listeria 
monocytogenes attached to product contact surfaces. J. Food Protec., 55, 246-251.

Parizzi, S. Q. F.; Andrade, N. J. Silva, C. A . S.; Soares, N. F. F. Silva, E. A. M. (2004) Adherence to different inert surfaces evaluated by epifluorescence microscopy and plate count. Braz. Arch. Biol. Technol. 47, 77-83.

Richardson , T; Mcgann, T. C. A. Kearney, R. D. (1980). Levels and locations of adenosine5'triphosphate in bovine milk. Journal of Dairy Science, 47, 91-96.
Velazquez, M.; Feirtag, J. M. (1997). Quenching and enhancement effects ATP extractants, cleansers, and sanitizers on the detection of the ATP bioluminescence. Journal of Food Protection, 60, 799-803.

Richardson, T.; McGann, T. C. A.; Kearney, R. D. (1980) Levels and locations of adenosine5'triphosphate in bovine milk. . Dairy Research, 47, 9196.

Velazquez, M.; Feirtag, J.M. (1997) Quenching and enhancement effectsof ATP extractants, cleansers, and sanitizers on the detection ofthe ATP bioluminescence signal. J. Food Protec., 60, 799-803. 
PÁGINA

EM

BRANCO 